\title{
CERTOS INTERESSES ALEMÃES NA ALTA SILÉSIA POLONESA: MUDANÇAS TERRITORIAIS E PROTEÇÃO DE MINORIAS
}

\author{
CERTAIN GERMAN INTERESTS IN POLISH UPPER SILESIA: TERRITORIAL CHANGES AND \\ PROTECTION OF MINORITIES
}

Felipe Nicolau Pimentel Alamino*

\begin{abstract}
Resumo:
O artigo busca analisar o caso julgado pela Corte Permanente de Justiça Internacional relativo a certos interesses alemães na Alta Silésia Polonesa, demonstrando as alterações territoriais ocorridas na Europa no pós-Primeira Guerra Mundial com relação à proteção das minorias existentes naqueles territórios que passariam a compor novos Estados, explorando as alterações referentes à Alemanha e à Polônia com relação às suas populações.

Palavras-chave: Proteção de Minorias. Corte Permanente de Justiça Internacional. Direito Internacional.
\end{abstract}

\begin{abstract}
:
The paper seeks to analyze the case judged by the Permanent Court of International Justice, concerning certain German interests in Polish Upper Silesia, demonstrating the territorial changes that occurred in Europe after World War I, regarding the protection of existing minorities in those territories that would make up new states. It also seeks to explore the changes regarding Germany and Poland with respect to their populations.
\end{abstract}

Keywords: Minorities protection. Permanent Court of International Justice. International Law.

Introdução

A Primeira Guerra Mundial trouxe diversas alterações no território europeu. Ao findar o conflito, as potências centrais, Império Austro-Húngaro, Império Otomano e Império Alemão, desapareceram, o que originou o aparecimento, e em alguns casos reaparecimento, de países recém-formados no Continente.

Além da própria separação entre Áustria e Hungria e os ganhos territoriais da Itália a expensas do antigo Império, da independência da Tchecoslováquia e da reorganização dos Estados balcânicos, destacam-se as mudanças territoriais sofridas pela Alemanha, que perderia territórios como a Alsácia e a Lorena para a França, porção da

* Doutorando em Direito Internacional pela Faculdade de Direito da Universidade de São Paulo - FDUSP. 
Alta Silésia para a Polônia, Memel, na atual Lituânia, passaria a compor, assim como Dantzig, na atual Polônia, Cidades-Estados sob tutela da recém-criada Liga das Nações.

Todas estas alterações acarretaram na preocupação do tratamento garantido a minorias étnico-linguísticas, que compunham anteriormente o grupo majoritário do antigo Estado soberano, dentro de Estados recém-formados ou nos territórios cedidos a outros Estados. Assim, as potências aliadas, vencedoras da Primeira Guerra, preocuparam-se em estabelecer tratados com os novos Estados surgidos do final do conflito com o objetivo premente de dar garantias fundamentais àqueles grupos, como o direito ao acesso ao governo em seu próprio idioma materno, além de, em muitos casos, ser-lhes franqueada a possibilidade de ensino no idioma materno, tão importante para a manutenção cultural daquele grupo minoritário.

Estas alterações, no entanto, não ficaram livres de questionamentos levados à Corte Permanente de Justiça Internacional, órgão judicial da Liga das Nações, responsável pela resolução de conflitos de interpretação do direito entre os Estados-partes. Diversos casos foram levados à Corte para que pudesse ser dada uma resolução sobre diversas questões relativas ao acesso às escolas minoritárias, a manutenção ou perda da nacionalidade de cidadãos naturais ou residentes nos territórios alvo das mudanças de soberania ou da legalidade da expropriação de propriedades com base na nacionalidade daquelas pessoas não consideradas nacionais devido às alterações territoriais.

Destes litígios, destaca-se o caso de Certos Interesses Alemães na Alta Silésia, julgado em maio de 1926, o qual será brevemente apresentado a seguir, relacionando-o com outros casos também envolvendo a Alemanha e a Polônia na Alta Silésia e a proteção das populações minoritárias daquela região.

\section{A Primeira Guerra Mundial e a reorganização europeia}

A Primeira Guerra Mundial (1914-1918) foi um dos fatores responsáveis pela reorganização territorial do continente europeu, após o desmembramento dos chamados Impérios Centrais ${ }^{1}$ e da crise originada no Império Russo com a Revolução de 1917. Estados históricos, como o caso da Polônia, ${ }^{2}$ ressurgiram, fazendo parte da sociedade internacional, ao passo que outros, como os estados bálticos, ${ }^{3}$ ainda que por um

Correspondem a Império Alemão, Império Austro-Húngaro e Império Otomano.

2 A Polônia deixara de existir após as quatro divisões (1772, 1793, 1795 e 1815) entre Rússia, Prússia e Áustria, o que fizera a Polônia histórica ter seus territórios divididos entre três importantes impérios à época da Primeira Guerra: Áustria-Hungria, Alemanha e Rússia (BECKER, 2010, p. 93-94), sendo considerável, como se verá na análise do Caso de Certos Interesses Alemães na Alta Silésia que a Polônia não teria entrado em guerra contra a Alemanha, mas contra a Rússia, principalmente, em busca de sua independência.

3 Lituânia, Letônia e Estônia. Destes, apenas a Lituânia pode ser considerada um estado histórico, tendo surgido no período medieval, formando, ainda no século XIV, um dos principais poderes políticos europeus 
período de tempo exíguo, ${ }^{4}$ despontavam no cenário internacional, pela primeira vez como estados independentes.

Estas alterações territoriais, ocorridas após o armistício de 11 de novembro de 1918, tiveram como inspiradoras, em certa medida, o discurso do então presidente dos Estados Unidos, Woodrow Wilson, endereçado às duas casas do Congresso Americano, em que se estabeleciam quatorze medidas que, caso fossem respeitadas poderiam promover a segurança coletiva e evitar que outra guerra surgisse envolvendo o planeta como a Primeira Guerra Mundial.

Entre os Quatorze Pontos (WILSON, 1918), o presidente americano proclama a independência da Rússia (ponto IV), dos Bálcãs (ponto XI) e da Polônia (ponto XIII). Para tanto, uma nova organização fronteiriça europeia deveria ser estabelecida, com a correspondente troca de territórios entre Estados já estabelecidos e com o redesenho dos limites dos Estados já formados com os novos Estados que surgiram com o final da guerra.

Estas novas divisões territoriais foram previstas no Tratado de Versalhes, de 1919, que colocou a termo à Primeira Guerra Mundial, com relação à Alemanha, outros quatro grandes tratados ${ }^{5}$ foram assinados entre as potências vencedoras e os demais Estados derrotados. (MOUGEL, 2014, p. 63-64). A parte III do mencionado Tratado traz cláusulas políticas para a Europa, com disposições acerca dos Estados ocupados pela Alemanha durante a guerra, como Bélgica (arts. 31-39), além de territórios que mudaram de soberania como a Alsácia e a Lorena ${ }^{6}$ (arts. 51-79), a cidade de $\mathrm{Memel}^{7}$ (art. 99), a Cidade-Livre de Dantzig ${ }^{8}$ (arts. 100-108) e outros Estados que surgiram após o conflito e passariam a fazer fronteira com a Alemanha, como a Tchecoslováquia (arts. 81-86) e

(SUBTELNY, 2009, p. 70).

4 Seriam anexados pela União das Repúblicas Socialistas Soviéticas na década de 1940.

5 O Tratado de Saint-Germain-em-Laye de 19 de setembro de 1919 com a Áustria, o Tratado de Trianon, de 2 de junho de 1920, com a Hungria (estes dois Estados foram separados no final da Primeira Guerra, não mais compondo o Império Austro-Húngaro), o Tratado de Neuilly-sur-Seine, de 27 de novembro de 1919, com a Bulgária e o Tratado de Sèvres, de 10 de agosto de 1920, com a Turquia, que seria substituído pelo Tratado de Lausanne de 24 de julho de 1923.

6 Após a Primeira Guerra Mundial, passaram a fazer parte do território francês.

7 Inicialmente cidade livre, passaria a fazer parte do território da Lituânia na década de 1920 (CASELLA, 2009, p. 861). Importante porto no nordeste da Prússia Oriental, cuja população da cidade era majoritariamente alemã, enquanto os campos periféricos eram lituanos. A cidade fora ocupada por tropas francesas no pósguerra até que os lituanos se apossaram da cidade, em 1924, o que fora admitido pela Liga das Nações (BECKER, 2010, p. 96).

8 Atual Gdansk, na Polônia, possuía, à época, uma população de aproximadamente 300 mil habitantes, quase na totalidade de idioma alemão. Isto impossibilitou o plano inicial de se permitir a transferência territorial deste importante porto europeu à soberania polonesa, passando a ser defendida, sobretudo pelo Reino Unido, na figura de seu Primeiro-ministro Lloyd George, a política da criação de uma Cidade-Livre, administrada pela Liga das Nações, onde a Polônia gozaria de facilidades portuárias - uma solução que não convinha nem aos poloneses, nem aos alemães (BECKER, 2010, p. 95-96). 
a Polônia (arts. 87-93), ${ }^{9}$ encontrando-se a importante região mineradora e industrial da Silésia entre os territórios que passariam a ser reorganizados.

A região da Silésia, importante para a análise do caso proposto, especificamente, fora demandada pela delegação polonesa na Conferência de Paz em Versalhes, haja vista que esse território possuía uma população de aproximadamente 70\% de poloneses (KOROWICZ, 1946, p. 9-10), o que não seria obstaculizado pelas potências vencedoras, havendo o projeto de divisão do território em sua maior porção para a Polônia e o restante para a Alemanha, ainda que uma pequena parcela fosse destinada à Tchecoslováquia. $\mathrm{O}$ art. 83 do Tratado de Versalhes passaria à soberania tchecoslovaca a porção da Silésia, composta pela região da cidade de Leobschütz (Głubczyce) e Hlučín, ao passo que a região da Alta Silésia, composta por importantes cidades como Ratibor (Racibórz) e Krzanowice, passariam à soberania polonesa (arts. 88-89).

$\mathrm{Na}$ parte da Silésia que seria passada à soberania polonesa, para que fosse confirmada essa transferência de soberania, todavia, permitiu-se que os cidadãos da região demarcada pudessem se manifestar, via plebiscito, para demonstrar se desejavam fazer parte do novo Estado polonês ou permaneceriam como membros da Alemanha, conforme previsto no anexo ao art. 88 do Tratado de Paz de Versalhes. (KOROWICZ, 1946, p. 11).

Segundo este documento, após 15 dias de entrada em vigor do Tratado de Versalhes, a região demarcada pela Comissão Internacional seria evacuada de tropas alemãs, passando a ser administrada pela autoridade internacional da Comissão que designaria quatro membros provenientes das potências, Estados Unidos, Itália, França e Reino Unido, para que pudessem ser realizadas as votações, em até seis meses, com a segurança sendo garantida pelas forças armadas das potências vencedoras.

É interessante destacar que a disposição anexa ao art. 88 do Tratado de Versalhes garantia o poder de voto a todas as pessoas, independentemente do sexo, ${ }^{10}$ maiores de 20 anos que tenham nascido na região do plebiscito ou que tenham sido domiciliados pelo tempo que a Comissão houver determinado. Esta interessante definição gerou, todavia, um grande influxo de população alemã, trazendo emigrados silesianos que se encontravam em diversas regiões alemãs para poder participar do plebiscito, o que permitiu, em grande medida a vitória alemã no plebiscito, ${ }^{11}$ ainda que fosse considerada,

\footnotetext{
9 A questão da Alta Silésia não seria a única territorial envolvendo a Polônia. Questões relativas à Galícia com o antigo Império Austro-Húngaro e com a Rússia também causaram dificuldades a efetivação da demarcação definitiva das fronteiras daquele país (BECKER, 2010, p. 99).

$10 \mathrm{O}$ que demonstra um avanço enorme, haja vista que no Brasil, por exemplo, às mulheres só seria franqueado o direito a voto na década de 1932, com o Decreto n. 21.076.

11 Realizado pouco antes da última revolta polonesa, em 21 de março de 1921, com 717 mil votos próAlemanha (62\%) e 434 mil votos a favor da Polônia, 38\% (BECKER, 2010, p. 98).
} 
mesmo à época como uma farsa eleitoral (KOROWICZ, 1946, p. 12), em meio aos problemas bélicos que vivia a região.

A corrida pela participação no pleito eleitoral ocorreu em um momento em que a região se encontrava em clima bélico, haja vista que, entre os anos de 1919 e 1921 , estouraram três insurreições polonesas, ${ }^{12}$ contrárias às forças policiais alemãs que, mesmo durante o período de controle da Comissão Internacional, como autoridade máxima do território, atuavam no território demarcado para o plebiscito, nesta fase de transição.

De todas as insurreições, a mais furiosa fora a terceira, com um movimento armado bem preparado pelos poloneses que acabaram enfrentando tropas alemãs militares disfarçadas, uma vez que tanto o Armistício quanto a Convenção de Paz impediam que tropas do exército alemão pudessem intervir, assim as tropas utilizadas foram milícias integradas por ex-combatentes, os chamados Freikorps. (BECKER, 2010, p. 97).

Este estado de coisas fez o Conselho Supremo das Principais Potências ${ }^{13}$ decidir, em 12 de agosto de 1921, por demandar à Liga das Nações a legalidade relativa a um traçado geográfico que dividiria a Alta Silésia conforme, em certa medida, a vitória territorial das tropas polonesas. O objetivo principal era tomar medidas que garantissem, durante um período transitório de readaptação a continuidade da vida econômica na região, haja vista que era constituída de uma importante região industrial mineradora, além de visar, também, à garantia da proteção de minorias, o trabalho do Conselho, permitindo um traço divisório entre os territórios alemães e poloneses demonstrou a capacidade da Liga das Nações em agir em momentos de crise. (KOROWICZ, 1946, p. 14).

A decisão do Conselho também estabelecera que tanto a Alemanha quanto a Polônia deveriam estabelecer uma convenção para resolver disposições transitórias, em um período máximo de quinze anos relativos às ferrovias, ao abastecimento de água e eletricidade, ao serviço postal, às aduanas, às questões econômicas, assim como às questões de nacionalidade, domicílio e de proteção de minorias, dentre outras questões, para tanto, seria necessário criar-se uma Comissão Mista da Alta Silésia e um tribunal arbitral capaz de julgar eventuais diferendos. (KOROWICZ, 1946, p. 15-16).

A situação finalmente colocada em prática pela Conferência dos Embaixadores, instituiria a repartição territorial em 1922, com os dois Estados tomando posse de seus territórios atribuídos e a saída das tropas aliadas, permitindo que o policiamento e as demais garantias legais fossem controladas pela Alemanha e pela Polônia, cada uma em seu lado da fronteira.

\footnotetext{
12 Comandadas por um ex-deputado polonês contra os alemães, Korfanty, no dia 17 de agosto de 1919, 20 de agosto de 1920 e 3 de março de 1921 (BECKER, 2010, p. 97).

13 Os vencedores da Primeira Guerra Mundial.
} 
Com este arranjo, que sofreu pressão francesa para garantir à Polônia mais território do que garantido pelo plebiscito, além de permitir a este Estado, do ponto de vista econômico, 75\% da produção carvoeira, três quartos das minas de chumbo e de zinco e 70\% da produção siderúrgica. (BECKER, 2010, p. 98-99).

Desta forma, a Polônia ${ }^{14}$ recebera $3.213 \mathrm{~km}^{2}$, com uma população de 892.547 pessoas, destes 263.950 de idioma exclusivamente alemão, ${ }^{15} 37.081$ de idioma alemão e polonês e 584.873 de idioma materno polonês, sendo, portanto, majoritariamente uma população polonesa. À Alemanha coube um território de $7.522 \mathrm{~km}^{2}$, com uma população de 1.046.019 pessoas, das quais 402.980 de idioma materno alemão, 51.259 bilíngues, 572.337 de idioma materno polonês, além de 19.463 pessoas que não tinham como língua materna nenhum dos dois idiomas, o que constituía uma maioria, no território alemão da fronteira, de população polonesa. (KOROWICZ, 1946, p. 18).

Antes de avançarmos para a análise do caso Certos Interesses Alemães na Alta Silésia, julgado pela Corte Permanente de Justiça Internacional, faz-se necessário discorrermos sobre a criação de novas minorias nestes territórios que sofreram alterações de soberania, além de cuidar do sistema de tratados criado no seio da Liga das Nações relativo aos Estados que receberam novos territórios e às principais potências aliadas vencedoras da Primeira Guerra Mundial, documentos estes que cuidavam do tratamento dos grupos de população minoritária e seu acesso à educação e demais direitos fundamentais, os chamados Tratados sobre Minorias.

\section{Tratados Minoritários e os novos Estados europeus}

O conceito de minoria em direito internacional é bastante controverso, não possuindo uma declaração juridicamente vinculante para o termo (BARTEN, 2015, p. 6), ainda que sua proteção possa ser traçada desde o Tratado de Osnabruque concluído em razão da paz de Vestfália, de 1648, cuidando de minorias religiosas, no caso cristãs, garantindo à minoria protestante, a liberdade de culto. (ACCIOLY; NASCIMENTO E SILVA; CASELLA, 2017, p. 518).

Barten, em sua pesquisa com relação à definição do termo no direito internacional, reconhece que a mais aceita de todas as definições é a proposta por Francesco Capotorti, em 1977, enquanto Relator Especial das Nações Unidas da Subcomissão sobre

14 À Polônia corresponderia $32 \%$ do território e $46 \%$ da população.

15 Interessante destacar que a minoria alemã no território polonês no imediato pós-guerra, ou seja, antes da partilha da Alta Silésia, compunha-se de 500 mil indivíduos, não sendo o grupo minoritário mais numeroso, tendo os ucranianos 4 milhões de pessoas, judeus (para fins do levantamento a população de religião judaica fora considerado como um grupo minoritário próprio) 2.400 milhões e bielorrussos 1.300 milhão (BECKER, 2010, p. 124). 
a Prevenção contra a Discriminação e Proteção de Minorias. Para Capotorti, minoria seria um grupo numericamente inferior ao resto da população do Estado, em uma posição não dominante, cujos membros, sendo nacionais do Estado, possuem características étnicas, linguísticas e religiosas diferentes do resto da população e demonstram, ainda que apenas de maneira implícita, um sentido de solidariedade, dirigido à preservação de sua cultura, tradições, religião e idioma. (CAPOTORTI, 1991, § 568, p. 96).

Capotorti (1991, § 21, p. 5) também lembra que a própria Corte Permanente de Justiça Internacional pode se manifestar sobre o conceito de minoria em um Parecer Consultivo de 31 de julho de 1930 no contexto da emigração das comunidades Grecobúlgaras, fazendo referência à Convenção, de 1919, entre a Bulgária e a Grécia em que eram trazidas estipulações acerca da proteção de minorias dentro dos territórios dos dois Estados, dentro do contexto dos tratados de paz referentes à Primeira Guerra Mundial, responsáveis pela criação de um sistema de proteção às minorias, baseado nos Tratados entre as potências vencedoras e os Impérios Centrais, entre as potências vencedoras e outros Estados vencedores da guerra ou recém-criados e até mesmo acordos bilaterais, como a já citada Convenção entre a Bulgária e a Grécia, assinada em Neuilly-sur-Seine, em 1919. (CONVENTION..., 1919).

Os tratados de paz entre as potências vencedoras da Primeira Guerra mundial e os Impérios Centrais, derrotados na guerra, trouxeram estipulações sobre a proteção de minorias, como os arts. 62 a 69 do Tratado de Saint Germain-en-Laye (TREATY..., 1919a) com a Áustria; o Tratado de Neuilly-sur-Seine (TREATY..., 1921b), com a Bulgária, em seus arts. 49 a 57; os arts. 54 a 60 do Tratado de Trianon (TREATY..., 1920) com a Hungria; os arts. 140 a 151 do Tratado de Sèvres (THE TREATY..., 1924) com a Turquia, assim como o documento que o substituiu, o Tratado de Lausanne (TREATY..., 1923) em seus arts. 37 a 45 .

Além dos tratados de paz entre os vitoriosos e as potências derrotadas, os novos Estados surgidos no pós-guerra e até mesmo alguns Estados vencedores da guerra que receberam porções territoriais, como a Romênia (TREATY..., 1921a), o Estado ServoCroata-Esloveno (TREATY..., 1919b) e a Grécia (TREATY..., 1999) assinaram tratados multilaterais com as principais potências aliadas e associadas contendo cláusulas também de proteção às minorias, demonstrando que o cuidado com os grupos minoritários acabou por constituir, em certa medida, a tônica do trabalho inicial da Liga das Nações logo após a Grande Guerra.

Estes tratados cuidaram da relação entre minorias étnicas, linguistas e religiosas nos territórios dos Estados especificados, garantindo o mesmo tratamento que a população majoritária, direito de culto e de acesso ao ensino às crianças nestes Estados em suas línguas maternas e também no idioma oficial, garantido pelo próprio governo, 
que deveria considerar a proporção populacional de nacionais de idioma minoritário ao desenvolver suas políticas educacionais.

Destaca-se, porém, que embora os tratados minoritários tenham surgido no pós-guerra, este tratamento específico a grupos minoritários só eram aplicados aos poderes derrotados, aos Estados recém-criados e a alguns Estados que lutaram ao lado dos vencedores, ${ }^{16}$ não se aplicando às principais potências vencedoras da guerra que continuavam a gerenciar suas colônias ou grupos minoritários dentro da metrópole sem o mesmo nível de proteção (CASSESE, 2008, p. 24), exemplo disto é a inexistência de tratados garantindo o mesmo tipo de proteção à população alemã incorporada ao território francês com a Alsácia e a Lorena. Desta forma, pode-se denotar que a inserção de proteção de minorias no cenário internacional, embora inovadora, atenuava o direito dos grupos étnicos ou linguísticos em buscar sua autodeterminação, além de ser seletiva na aplicação, limitando-se geograficamente às porções oriental e central da Europa, mas não às Principais Potências, os Estados ocidentais. (CASSESE, 2008, p. 27).

Dos Estados surgidos no pós-guerra, a Polônia ${ }^{17}$ destaca-se por ter assinado dois tratados cujos conteúdos traziam previsões específicas com relação a minorias. Inicialmente, ainda em 1919, este país e as Principais Potências Aliadas, quais sejam Império Britânico, França, Itália, Japão e Estados Unidos assinaram em Versalhes (MINORITIES..., 1919) um documento exclusivamente para tratar da temática de minorias, garantindo a seus nacionais pertencentes a minorias raciais, ${ }^{18}$ religiosas ou idiomáticas os mesmos tratamentos e segurança jurídica que os demais nacionais poloneses (art. 8), garantindo quantia equitativa nos fundos públicos para propostas educacionais, beneficentes e religiosos (art. 9), sendo consideradas todas as questões relativas às minorias obrigações internacionais sob a garantia da Liga das Nações (art. 12).

Alguns anos após, em 1922, devido aos desentendimentos ocorridos à região da Alta Silésia, Alemanha e Polônia reunidos em Genebra, na Suíça, assinariam novo tratado com o objetivo de garantir a fluidez da vida econômica, o que era um interesse comum às partes, haja vista que a região demarcada era um importante polo industrial e mineiro europeu, rica em carvão mineral e minério de ferro. Este tratado, a Convenção Germano-Polonesa relativa à Alta Silésia (CONVENTION..., 1922), também objetivava garantir a proteção das minorias no território que fora partilhado por via do plebiscito organizado no ano de 1921, porém, este segundo documento se limitaria especificamente

\footnotetext{
16 Como os já citados Romênia, Grécia e Sérvia (que viria a formar, após a guerra, o Estado servo-croataesloveno).

17 E a Alemanha, como veremos na Convenção relativa à Alta Silésia.

18 Conforme linguagem usada no período do documento.
} 
à região geográfica da Alta Silésia, além de considerar um período de aplicação diferente para cada parte contratante.

O tratado seria aplicado ao território alemão da Alta Silésia por um período transitório de 15 anos, ao passo que ao território polonês, a Polônia reconhecia a aplicação de pleno direito de toda a proteção minoritária contida no Pequeno Tratado de Versalhes (art. 65), uma vez que as disposições relativas à proteção de minorias remetiam aos artigos referentes do Tratado de 28 de junho de 1919. Este tratado, portanto, garantia igualdade de tratamento a todos os cidadãos no território da Alta Silésia, independentemente de sua fé, seu idioma materno ou sua origem étnica, garantindo inclusive acesso às escolas minoritárias, ou seja, escolas no idioma materno da população destacada. ${ }^{19}$

Não obstante, e de especial destaque, as disposições gerais da Convenção de 1922, arts. 73 e 74, trazem estipulações que impedem aos Estados contratantes tomarem medidas legislativas, administrativas e judiciárias que sejam contrárias às proteções às minorias garantidas pelo instrumento internacional, além de impedir que os Estados procedam com métodos que verifiquem ou contestem o pertencimento de determinado indivíduo à determinada minoria.

O tratamento destas minorias no território da Alta Silésia seria, como se verá à continuação, tema de diversos casos envolvendo os dois Estados (Alemanha e Polônia) na Corte Permanente de Justiça Internacional, sobretudo o caso relativo a Certos Interesses Alemães na Alta Silésia Polonesa, onde os demais artigos da Convenção de 1922, relativos às propriedades dos residentes no território partilhado seriam analisados com relação ao direito de cidadãos não poloneses em manterem suas propriedades naquela parcela geográfica pertencente à Polônia.

\section{Caso relativo a Certos Interesses Alemães na Alta Silésia Polonesa}

O caso relativo a Certos Interesses Alemães na Alta Silésia Polonesa referese a discussões acerca da aplicação dos tratados que a Polônia ou que a Alemanha eram signatários com relação a cláusulas que garantiriam a expropriação de propriedades dos territórios que, anteriormente, eram alemães e cujos proprietários fossem diretamente relacionados com o Estado alemão.

Ao final da Primeira Guerra Mundial, a assinatura da Convenção do Armistício de 11 de novembro de 1918 e seu subsequente Protocolo de Spa, de $1^{\circ}$ de dezembro de 1918, obrigavam a Alemanha, durante o período em que durasse o armistício,

19 Conforme os arts. 69 e 70 da Convenção Germano-Polonesa e arts. 9, alíneas I e II e 10 do Pequeno Tratado de Versalhes. 
isto é, até a assinatura do Tratado que colocaria fim à guerra, ${ }^{20}$ a não tomar nenhuma ação que fosse passível de diminuir o valor dos seus bens, para assim garantir aos Estados Aliados, vencedores do conflito, uma forma de reparação a suas perdas decorrentes do esforço de guerra, com especial atenção a bens como ferrovias, canais, minas, bosques, empresas coloniais, empresas industriais ou empresas comerciais, sendo considerada qualquer atitude contrária à proibição como nula em sua totalidade. (PERMANENT COURT OF INTERNATIONAL JUSTICE, 1926, p. 25-26).

Finalmente, o Tratado de Versalhes também dispunha, em seu art. 256, que as Potências vencedoras, que receberam territórios anteriormente alemães, deverão adquirir todas as propriedades e posses do Império ou dos Estados alemães, ou ainda da Coroa, do então Imperador e das demais famílias reais, com o valor destas aquisições sendo fixadas pela Comissão de Reparação e pagos pelos Estados adquirentes diretamente a esta Comissão, na forma de crédito do Governo alemão, a ser debitado do total devido por este às Potências vencedoras. (TREATY..., 1919c).

Não obstante à existência destes tratados, a lei polonesa de 14 de julho de 1920, especificamente em seus arts. I, II e V estabelecia que as propriedades pertencentes à Coroa, ao Império Alemão, aos Estados Alemães, às instituições dos Estados ou do Império Alemão, ao antigo imperador, ${ }^{21}$ ou às demais casas reinantes, após o dia 11 de novembro de 1918, ${ }^{22}$ passariam ao Tesouro Polonês. Estas propriedades, por sua vez, caso houvessem sido alienadas, passando a novos proprietários, após a data do Armistício, poderiam ser expropriadas pelo Tesouro Polonês, que despejaria os novos proprietários e administraria diretamente os bens. (PERMANENT COURT OF INTERNATIONAL JUSTICE, 1926, p. 23-24).

Outrossim, a já citada Convenção Germano-polonesa, de 1922, garantia à Polônia o direito de expropriar ${ }^{23}$ indústrias controladas por alemães ${ }^{24}$ (art. 7), além de expropriar propriedades agrícolas de mais de 100 hectares daqueles cidadãos alemães que não tiveram reconhecido seu direito de conservar domicílio na Alta Silésia Polonesa, ${ }^{25}$ ou de propriedade de sociedades controladas por cidadãos alemães nestas condições (art. 12).

$20 \quad$ O Tratado de Versalhes de 28 de junho de 1919.

21 O Kaiser Guilherme II.

22 Data da assinatura do Armistício de Compiègne, que colocaria fim aos embates da Primeira Guerra Mundial.

23 Dentro de um período de até quinze anos, contados a partir de 15 de abril de 1922, exatamente um mês antes da assinatura da Convenção.

24 Expropriação que deveria ser aceita pela Comissão Mista, responsável por acompanhar as alterações no território da Alta Silésia, e considerada como indispensável para manter a exploração industrial, seguindo o objetivo da Convenção, qual seja, manter o pleno funcionamento da vida econômica no território destacado.

25 O título IV da Convenção trata da questão da manutenção do domicílio. O art. 40 traz a possibilidade de cidadãos que houverem optado pela nacionalidade alemã permanecerem com domicílio na Alta Silésia Polonesa por um período de quinze anos. Da mesma forma, o art. 41 garantia aos cidadãos que optassem pela nacionalidade polonesa manterem o domicílio na Alta Silésia alemã por igual período de quinze anos. 
A interpretação destas disposições permitiria, na perspectiva do governo polonês, pleitear expropriar diversas propriedades situadas em sua porção territorial da Alta Silésia, sendo elas uma Fábrica em Chorzów $^{26}$ e propriedades rurais de diversos proprietários, sendo eles o Conde Nikolaus Ballestrem, a Empresa Giesche, Christian Kraft (o Príncipe Hohenlohe-Oehringen), a Empresa Vereinigte Königs- und Laurahütte, a Baronesa Von Goldschmidt-Rothschild, Karl Maximilian (o Príncipe de Lichnowsky), a Cidade de Ratibor, a Empresa Godulla, o Duque de Ratibor e o Conde Saurma-Jeltsch e, por dar iniciativa ao processo de expropriação destas propriedades, o governo alemão levou o caso à Corte Permanente de Justiça Internacional para que julgasse a legalidade destes atos jurídicos.

A Corte, ao analisar o caso, reviu os documentos segundo os quais se embasavam os pleitos poloneses de expropriação, fazendo interessantes esclarecimentos acerca das disposições dos tratados, a começar pela análise dos documentos que encerraram o conflito bélico entre a Alemanha e os países vitoriosos.

No entendimento da Corte, a Polônia não era parte contratante nem da Convenção de Armistício, nem do Protocolo de Spa, uma vez que à época da conclusão dos dois documentos, a Polônia não era considerada como beligerante pela Alemanha, portanto impossível de ter concluído documentos como armistícios, ainda que as Principais Potências Aliadas considerassem as forças polonesas como uma entidade autônoma, cobeligerante, aliada, esta não se encontrava em guerra com a Alemanha, o que explicaria sua ausência no Tratado de Versalhes como uma Potência Aliada, ${ }^{27}$ sendo assim, não estaria apta a receber os direitos de reparação provenientes do art. 232 deste Tratado (PERMANENT COURT OF INTERNATIONAL JUSTICE, 1926, p. 28), não obstante, a Corte também entendeu possível a possibilidade da Alemanha dispor de suas propriedades até o período em que a transferência de soberania sobre o território se efetivasse (PERMANENT COURT OF INTERNATIONAL JUSTICE, 1926, p. 30) e, o que é de maior destaque, que a lei polonesa de 1920 encontrava-se em descompasso com a Convenção de 1922 no que toca as propriedades situadas na Alta Silésia Polonesa. (PERMANENT COURT OF INTERNATIONAL JUSTICE, 1926, p. 24).

Assim, passando a análise de cada propriedade, a Corte inicialmente cuidou do caso da Fábrica de Chorzów, cujo pleito polonês consistia no fato de o Império Alemão ter fraudado o direito, haja vista que teria sido vendida pelo Reich, no dia 24 de dezembro de 1919 (PERMANENT COURT OF INTERNATIONAL JUSTICE, 1926, p.

\footnotetext{
26 Königshütte, em alemão.

27 A Polônia é considerada pela Corte como parte do Império Russo durante o conflito mundial, portanto a ela caberia em tese o disposto no art. 116 do Tratado de Versalhes, com relação à independência dos antigos territórios russos ser respeitada pela Alemanha, ao passo que as reparações seriam aptas apenas ao estado Russo, não aos Estados recém-independentes do Império.
} 
35-36), à empresa Oberschlesische Stickstoffwerke A.-G., uma empresa formada para a aquisição, construção e exploração de trabalhos com nitrato e indústria química em geral, controlada por outra empresa alemã a Bayerisch Stickstoffwerke A.-G., que, desde 1915 era responsável por administrar pelo Reich Alemão a fábrica (PERMANENT COURT OF INTERNATIONAL JUSTICE, 1926, p. 43), sendo considerado, portanto pela Polônia, como uma fraude ao direito, eximindo-se a Alemanha da obrigação de dispor de sua propriedade imperial ao estado polonês.

A Corte entende, todavia, que, caso a transferência de propriedade não tivesse sido operada, a Polônia sofreria danos econômicos, contrários aos ditames da Convenção Germano-Polonesa sobre a Alta Silésia, haja vista que fatalmente a fábrica teria suas funções terminadas, sendo fechada, o que causaria grande perda econômica à região, assim, o pleito polonês de que a manobra alemã seria um ato in fraudem creditorum seria infundado (PERMANENT COURT OF INTERNATIONAL JUSTICE, 1926, p. 39), não sendo aplicável, portanto o art. 256 do Tratado de Versalhes, uma vez que a transferência de propriedade fora legal, tratando-se de uma fábrica controlada pela empresa alemã Oberschlesische, o que permitiria a aplicação da Convenção de 1922 acerca da possibilidade de expropriação de propriedades alemãs no território da Alta Silésia.

Esta questão fugiria, porém, do escopo da Corte no caso em questão, haja vista que o governo polonês não havia levantado este ponto de disputa, nem como questão subsidiária (PERMANENT COURT OF INTERNATIONAL JUSTICE, 1926, p. 41), assim, a expropriação da fábrica em Chorzów seria contrária ao direito, o que não impediria que este tema voltasse à Corte, pouco depois, em 1928, para que esta se debruçasse acerca da possibilidade de indenizações à Alemanha por parte da Polônia. (PERMANENT COURT OF INTERNATIONAL JUSTICE, 1928a).

Com relação às propriedades rurais, a Corte demonstrou que a própria Convenção de $1922^{28}$ indica as condições necessárias para a expropriação. (PERMANENT COURT OF INTERNATIONAL JUSTICE, 1926, p. 46). O art. 15 alínea I indicava que ao governo polonês, caso demonstre intenção em expropriar uma propriedade rural de grande porte, deveria notificar o proprietário até o dia $1^{\circ}$ de janeiro de 1925 , devendo esta expropriação ocorrer até dois anos após a notificação (II) e, caso ocorra um atraso, passando a ser mais de dois anos para a expropriação, esta não poderia mais ocorrer (III).

A Corte também demonstrou que a Convenção garantia, pelo art. $9, \S 3^{\circ}$ que as propriedades rurais que serviam para atender as necessidades das grandes empresas, como produtoras de lenha, ou de matéria-prima em geral, deverão ser considerados como

28 O art. 23 da Convenção já garante a possibilidade da Corte se manifestar em razão de divergências com relação às aplicações dos arts. 6-22 deste documento. Estes artigos são relativos à expropriação de grandes indústrias e de grandes propriedades rurais. 
parte da própria indústria e não como propriedades rurais isoladamente. (PERMANENT COURT OF INTERNATIONAL JUSTICE, 1926, p. 48-50). Não obstante, a Corte também entendeu que para o bom desenvolvimento da indústria de mineração, os mineiros devem garantir a posse da superfície sobre a mina, do contrário encareceria o processo produtivo devido a compensações e indenizações causadas pelos distúrbios causados pela extração. (PERMANENT COURT OF INTERNATIONAL JUSTICE, 1926, p. 51-53).

Com base neste posicionamento, a Corte iniciou a análise de cada propriedade rural. Destas, podemos agrupar o caso da propriedade rural do Conde Nikolaus Ballestrem, 320 hectares no distrito de Swietochlowice (PERMANENT COURT OF INTERNATIONAL JUSTICE, 1926, p. 53), da Empresa Giesche (Giesche Spolka akcyjna) 3.150 hectares em Katowice (PERMANENT COURT OF INTERNATIONAL JUSTICE, 1926, p. 56-57), da Empresa Vereinigte Königs- und Laurahütte A.-G., 1.984 hectares no distrito de Rybnik (PERMANENT COURT OF INTERNATIONAL JUSTICE, 1926, p. 65-66) e da Empresa Godulla, composta por 3.495 hectares no distrito de Swietochlowice. (PERMANENT COURT OF INTERNATIONAL JUSTICE, 1926, p. 75). Todos estes casos, ao serem examinados pela Corte, foram concluídos como sendo propriedade rural, cuja superfície ou a produção de matéria-prima eram usadas para benefício da indústria mineradora, portanto não passíveis de expropriação.

A Corte também explicitou que com relação à Empresa Giesche a expropriação ocorrera com irregularidades na notificação (art. 15 da Convenção de 1922) o que também a tornaria imune à expropriação (PERMANENT COURT OF INTERNATIONAL JUSTICE, 1926, p. 58), enquanto que com a Empresa Vereinigte Königs- und Laurahütte, embora esta tivesse sede em Berlim, 80\% de suas ações pertenciam a quatro indivíduos: M. A. Weinmann, de Aussig, nacional tcheco, M. Bosel, de Viena, nacional austríaco, M. Askenazy, de Varsóvia e Príncipe Henckel Von Donnersmarck, de Neudeck, ambos nacionais poloneses, o que para os fins da Convenção de 1922 não seria possível concluir que se tratasse de uma empresa controlada por alemães (art. 6), ${ }^{29}$ portanto impossível de ser expropriada. (PERMANENT COURT OF INTERNATIONAL JUSTICE, 1926, p. 69-71).

As demais propriedades foram analisadas pela Corte, sendo considerada a propriedade de Christian Kraft, Príncipe de Hohenlohe-Oehringen, 361 hectares no distrito de Katowice como passível de expropriação, por ser o príncipe nacional alemão e sua propriedade, ainda que tivesse sida alugada pela empresa Hohenlohe-Werke, não era usada para o benefício e manutenção das funções industriais desta, fugindo,

29 O que difere do caso da Empresa Godulla. A maior parte dos acionistas desta empresa era de nacionalidade alemã, sendo assim, a única razão para não haver a expropriação da propriedade rural era o destino de produção, qual seja, a garantia da manutenção das funções da indústria mineradora que usava seu subsolo. 
portanto do escopo do art. 9, $\S 3^{\circ}$ da Convenção de 1922. (PERMANENT COURT OF INTERNATIONAL JUSTICE, 1926, p. 65). Com relação à propriedade da Baronesa Maria Anna von Goldschmidt-Rothschild, 1.618 hectares no distrito de Rybnik, a Corte concluiu que o governo polonês falhou, segundo o art. 15 da Convenção de 1922, com a notificação da expropriação da propriedade, portanto livre de expropriação. (PERMANENT COURT OF INTERNATIONAL JUSTICE, 1926, p. 71-72). Com relação à propriedade de Karl Maximilian, Príncipe de Lichnowsky, 1.930 hectares no distrito de Rybnik, a Corte reconheceu que pelo art. 84 do Tratado de Versalhes, por ser o Príncipe domiciliado em Kudulna (Kuchelna) em território da então recém-criada Tchecoslováquia, teria adquirido ipso facto a nacionalidade tchecoslovaca, perdendo a nacionalidade alemã, portanto, impassível de ter sua propriedade expropriada segundo o art. 17 da Convenção de 1922. (PERMANENT COURT OF INTERNATIONAL JUSTICE, 1926, p. 73).

Com relação ao domicílio do proprietário, a Corte também se manifestou com relação à propriedade do Duque de Ratibor, 495 hectares no distrito de Rybnik, nas comunas de Adamowice, Bogunice, Cwalecice, Raszczyce e Zwonowice. Segundo o art. 40 da Convenção de 1922, os nacionais alemães que tenham optado por ser domiciliados na Alta Silésia Polonesa teriam o direito de manter seu domicílio por quinze anos, não sendo, portanto, atingidos pelo art. 12 da mesma Convenção que garante a expropriação de propriedades de nacionais alemães que não tiveram seus direitos de domicílio garantidos. Todavia, a Corte demonstra que o Duque de Ratibor não deixa claro exatamente onde é seu domicílio, embora possa ser considerado que determinada pessoa tenha mais de um domicílio, não pode ser considerado que um mesmo domicílio se encontre em duas localidades, duas comunas ou mesmo dois estados diferentes (PERMANENT COURT OF INTERNATIONAL JUSTICE, 1926, p. 79), assim, como a porção da propriedade em que o Duque possuía seu domicílio, segundo disposição do art. 29 da Convenção de 1922, ${ }^{30}$ encontrava-se na porção territorial em território alemão, o governo polonês poderia manter a expropriação. (PERMANENT COURT OF INTERNATIONAL JUSTICE, 1926, p. 80).

Situação parecida foi encontrada pela Corte com relação à propriedade do Conde Wilhelm Saurma-Jeltsch, 439 hectares no distrito de Rybnik. A propriedade em questão encontrava-se dividia entre as comunas de Bukow, Kamien e Ligota Tworkowska e o domicílio do Conde Saurma-Jeltsch encontrava-se na porção territorial situada na parte alemã da fronteira, portanto, pelo disposto no art. 12 da Convenção de 1922, caberia à Polônia o direito de expropriação. (PERMANENT COURT OF INTERNATIONAL JUSTICE, 1926, p. 80-81).

30 Domicílio é o local onde determinada pessoa possui a concentração de suas atividades e interesses pessoais e econômicos. 
Finalmente, a Corte se manifestou, também, com relação à propriedade de 297 hectares localizada no distrito de Rybnik da Cidade de Ratibor. A Corte entendeu que, embora o conceito de empresa controlada por nacionais alemães não pudesse ser estendido a uma cidade, esta é formada pela base territorial e por seus habitantes que decidirão as leis municipais que a administrarão, portanto, por extensão, a Corte interpretou que a Cidade de Ratibor poderia ser considerada como de nacionalidade alemã para fins da Convenção de 1922, sendo passível de expropriação, salvo, com base no art. 12, § $2^{\circ}$ da Convenção, a área da propriedade que é composta por um bosque usado como recreação pela população local, chamada Waldpark, uma vez que não é de uso econômico. (PERMANENT COURT OF INTERNATIONAL JUSTICE, 1926, p. 74-75).

Desta forma, a Corte, ao julgar o caso relativo a Certos Interesses Alemães na Alta Silésia Polonesa, pode garantir o direito de empresas e nacionais alemães em manter suas propriedades em território polonês, salvo nos casos do Duque de Ratibor e do Conde Saurma-Jeltsch em que foram reconhecidos os direitos do estado polonês em expropriar as propriedades, um dos diversos casos relativos aos antigos territórios do Império Alemão e com relação a suas populações minoritárias.

\section{Casos relacionados a Certos Interesses Alemães na Alta Silésia Polonesa}

Ao longo das décadas de 1920 e 1930, a Corte Permanente de Justiça Internacional teve a oportunidade de julgar casos relativos a divergências entre a Alemanha e a Polônia.

Sem o objetivo de explicar cada um dos casos, passaremos a uma breve lista dos casos com o objetivo de demonstrar como as transferências territoriais ocorridas no pós-Primeira Guerra Mundial ensejou diversos problemas de adaptação aos territórios em questão.

Além do já estudado caso relativo a Certos Interesses Alemães na Alta Silésia Polonesa em que se demonstrou o destino das propriedades de nacionais alemães no novo território polonês, houve dois Pareceres Consultivos exarados pela Corte Permanente no ano de 1923 relativos a questões sobre a nacionalidade de seus cidadãos. Embora cada um dos pareceres tenham razões diferentes, o primeiro (PERMANENT COURT OF INTERNATIONAL JUSTICE, 1923a) relativo aos direitos de colonos de origem alemã nos territórios cedidos à Polônia, enquanto o segundo (PERMANENT COURT OF INTERNATIONAL JUSTICE, 1923b) trata sobre a aquisição de nacionalidade polonesa. Ambos os pareceres cuidam da forma como o governo polonês teria ignorado a população minoritária de origem étnica ou linguística alemã, com nacionalidade polonesa reconhecida pelo Tratado de Versalhes como sendo seus nacionais, situação que a Corte 
reconheceu não se encontrar em conformidade com as obrigações internacionais que a Polônia havia obtido.

Não obstante estes Pareceres Consultivos, a Corte também se deparou com um Caso relativo ao Direito das Minorias na Alta Silésia (Escolas Minoritárias) (PERMANENT COURT OF INTERNATIONAL JUSTICE, 1928b) em 1928, diretamente relacionado ao Parecer Consultivo relativo ao Acesso às Escolas Minoritárias Alemãs na Alta Silésia em 1931 (PERMANENT COURT OF INTERNATIONAL JUSTICE, 1931) em que se discutiu a possibilidade e o acesso de crianças de cidadania polonesa e de origem alemã, ou seja, de língua materna alemã, poderem frequentar escolas com aulas ministradas em alemão e a forma como se definiria quem poderia ter acesso a estas escolas.

Finalmente, em 1933, a Corte pode analisar o pedido de medida provisória relativa ao Caso relativo à Reforma Agrária Polonesa e a Minoria Alemã (PERMANENT COURT OF INTERNATIONAL JUSTICE, 1933), não vendo razão que indicasse a necessidade de medidas provisórias com relação a possível expropriação de propriedades de cidadãos poloneses de origem alemã por razão de o pedido não se encontrar em conformidade com os requisitos do art. 41 de seu Estatuto da Corte, podendo a Corte vir a julgar a conformidade da lei de reforma agrária polonesa no futuro.

Apesar de termos demonstrado todos estes casos relativos à Alemanha e à Polônia e mudanças territoriais no Pós-Primeira Guerra Mundial, a Corte pôde apreciar outros casos envolvendo alterações territoriais e populações minoritárias. Há, pelo menos, mais um caso em que se discutem as escolas minoritárias, desta vez envolvendo a Albânia e a população de religião e etnia diferente da maioria dos albaneses (PERMANENT COURT OF INTERNATIONAL JUSTICE, 1935) ou mesmo o caso relativo à Interpretação do Estatuto do Território de Memel (PERMANENT COURT OF INTERNATIONAL JUSTICE, 1932) que, embora não trate diretamente da população de Memel, envolve este tema, uma vez que este território, que anteriormente fizera parte da Prússia Oriental na Alemanha, passara a constituir uma Cidade-livre, como a cidade de Danzig (Gdansk), e posteriormente, em 1923, sofrera um golpe de força dos lituanos, incorporando a região ao seu território.

A população de Memel constituía aproximadamente 130 mil habitantes, pouco mais da metade de idioma lituano, predominantemente habitante da zona rural, enquanto nas cidades predominava população de língua alemã, mais rica e mais instruída do que a média dos lituanos. O território passaria a ser "lituanizado", com o nome de Klaipèda ainda que a Alemanha, por sua vez, enviasse professores de idioma alemão, também imbuídos da missão de propagar o nazismo, estimulando preconceitos e ódios raciais. (CASELLA, 2009, p. 861-862). Ainda que a lógica do Estatuto de Memel primasse pela autonomia do território e o respeito à soberania da Lituânia, conforme a interpretação da Corte em 1932, a Lituânia acabaria por interpretar a decisão de forma favorável a 
sua política de "lituanização", intervindo de forma violenta nas eleições seguintes em Memel, com prisões, acusações de traição e de ligações com o partido nazista, sendo muitas pessoas condenadas à morte, ainda que suas penas tenham sido comutadas em prisão. (CASELLA, 2009, p. 866).

\section{Conclusão}

As alterações territoriais decorrentes da Primeira Guerra Mundial além de reajustar o mapa europeu aumentou o conflito já existente com relação às populações minoritárias que já eram comuns nos Impérios Centrais e em regiões com população bastante diversificada como o Império Austro-Húngaro e os Bálcãs. Este conflito se dava pela forma como os Estados existentes tentavam governar sua população com projetos que visavam à maioria, de certa forma uniformizando, como vimos no caso da década de 1920 envolvendo Memel e a Lituânia, não respeitando as minorias étnicas, linguísticas e religiosas.

Estas mudanças territoriais criaram, no primeiro momento, um sistema de tratados multilaterais e bilaterais que procurava dar garantias mínimas às populações minoritárias dos Estados recém-surgidos com o ocaso dos impérios centrais, além de cuidar também das populações existentes nos Estados que tiveram acréscimos territoriais no pós-guerra, ainda que países como a França, considerado uma das Principais Potências Vencedoras, não fossem parte de tratados que estipulassem direitos e garantias específicos às populações minoritárias das regiões que passaram a integrar (ou reintegrar) seu território, como no caso da Alsácia e da Lorena.

Os tratados surgidos no período pós-guerra garantiam, de modo geral, acesso à educação em língua materna, daquelas populações étnica e linguisticamente diferentes do restante da população de seus Estados, liberdade religiosa, com liberdade de culto, dos grupos religiosos minoritários, como os judeus ou os cristãos em Estados como a Albânia e a Turquia, o que retomaria, em certa medida, conceitos já existentes na história do direito internacional desde a Paz de Vestfália, no século XVII, além de garantias de tratamento igualitário a todos os cidadãos do Estado signatário independentemente de sua origem.

A aplicação destas garantias, porém, não foi de todo efetivada, tendo como provas a grande quantidade de casos relativos às alterações territoriais, que afetaram as minorias populacionais em seus respectivos Estados.

O caso principal do presente artigo, Certos Interesses Alemães na Alta Silésia Polonesa, embora trate, à primeira vista, de questões relativas apenas a propriedades de origem alemã no território que fora transferido à Polônia, pode ser interpretado, também, como uma forma de política prejudicial do governo polonês aos cidadãos de origem 
étnica ou linguística diferente, no caso dos alemães, haja vista que diversas propriedades que foram analisadas pela Corte Permanente de Justiça Internacional não tiveram sua expropriação validada, tendo sido escolhidas para a expropriação, em um primeiro momento em razão de sua origem alemã, embora com o desenvolvimento do caso, restasse demonstrado que a escolha das propriedades para expropriação fora, em muitos casos, contrária às leis internacionais.

Estes casos da Corte Permanente de Justiça Internacional não têm apenas importância histórica. É notório como a história por vezes se repete, com inúmeros reajustes territoriais que as décadas posteriores à Primeira Guerra Mundial viram ocorrer, sobretudo no pós-Segunda Guerra Mundial e no período da descolonização nas décadas de 1960 e 1970.

Desta forma, o estudo dos casos relativos a alterações territoriais e minorias na experiência da corte do período da Liga das Nações se faz de suma importância para marcar a evolução da proteção internacional de minorias, além de possibilitar reflexões que levem a novas soluções para problemas antigos, mas que se repetem.

São Paulo, 27 de junho de 2020.

\section{Referências}

ACCIOLY, Hildebrando Pompeo Pinto; NASCIMENTO E SILVA, Geraldo Eulálio; CASELLA, Paulo Borba. Manual de direito internacional público. 23. ed. São Paulo: Saraiva, 2017.

BARTEN, Ulrike. What's in a name? Peoples, minorities, indigenous peoples, tribal groups and nations. Journal on Ethnopolitics and Minority Issues in Europe, Flensburg, v. 14, n. 1, p. 1-25, 2015 .

BECKER, Jean-Jacques. O tratado de Versalhes. Tradução de Constancia Egrejas. São Paulo: Unesp, 2010.

CAPOTORTI, Francesco. Study on the rights of persons belonging to ethnic, religious and linguistic minorities. New York: United Nations, 1991.

CASELLA, Paulo Borba. Direito internacional dos espaços. São Paulo: Atlas, 2009.

CASSESE, Antonio. Self-determination of peoples: a legal reappraisal. Cambridge: Cambridge University Press, 2008.

KOROWICZ, Marc-Stanislas. Une expérience de droit international: la protection des minorités de Haute-Silésie. Paris: A. Pedone, 1946.

MOUGEL, François-Charles; PACTEAU, Séverine. Histoire des relations internationales: de 1815 à nos jours. 11e. ed. Paris: Presses Universitaires de France, 2014. 
WILSON, Woodrow. Address of the President of the United States: delivered at a joint session of the two houses of Congress. Washington, DC: Govt. Print off, Jan. 1918. Disponível em: https:// babel.hathitrust.org/cgi/pt?id=mdp.39015074797914\&view=1up\&seq=3. Acesso em: 13 out. 2019.

\section{Documentos}

CONVENTION between Greece and Bulgaria respecting reciprocal emigration. Neuilly-sur-Seine, Nov. 1919. Disponível em: http://www.pollitecon.com/html/treaties/Convention_Between_Greece And_Bulgaria_Respecting_Reciprocal_Emigration.htm. Acesso em: 21 nov. 2019.

CONVENTION Germano-Polonaise: relative a la Haute Silésie. Genève: Impr. Albert Kundig, mai 1922. Disponível em: https://www.sbc.org.pl/dlibra/publication/147893/edition/138867/ content?ref=desc. Acesso em: 20 nov. 2019.

MINORITIES treaty between the principal allied and associated powers (the British Empire, France, Italy, Japan and the United States) and Poland. Versailles, June, 1919. Disponível em: http:// ungarisches-institut.de/dokumente/pdf/19190628-3.pdf. Acesso em: 17 out. 2019.

PERMANENT COURT OF INTERNATIONAL JUSTICE. Collection of advisory opinion. Advisory opinion given by the Court on September $10^{\text {th }} 1923$ on certain questions relating to settlers of German origin in the territory ceded by Germany to Poland. Leyden: A. W. Sijthoff's Publishing Company, 1923a. Disponível em: https:/www.icj-cij.org/public/files/permanentcourt-of-international-justice/serie_B/B_06/Colons_allemands_en_Pologne_Avis_consultatif.pdf. Acesso em: 10 nov. 2019.

PERMANENT COURT OF INTERNATIONAL JUSTICE. Collection of advisory opinion. Acquisition of Polish Nationality. Leyden: A. W. Sijthoff's Publishing Company, 1923b. Disponível em: https://www.icj-cij.org/public/files/permanent-court-of-international-justice/serie_B/B_07/01_ Acquisition_de_la_nationalite_polonaise_Avis_consultatif.pdf. Acesso em: 10 nov. 2019.

PERMANENT COURT OF INTERNATIONAL JUSTICE. Collection of judgments. Case concerning certain German interests in Polish Upper Silesia. Leyden: A. W. Sijthoff's Publishing Company, 1926. Disponível em: https://www.icj-cij.org/public/files/permanent-court-ofinternational-justice/serie_A/A_07/17_Interets_allemands_en_Haute_Silesie_polonaise_Fond Arret.pdf. Acesso em: 23 out. 2019.

PERMANENT COURT OF INTERNATIONAL JUSTICE. Collection of judgments. Caso concerning the factory at Chorzów: (claim for indemnity). Leyden: A. W. Sijthoff's Publishing Company, 1928a. Disponível em: https://www.icj-cij.org/public/files/permanent-court-ofinternational-justice/serie_A/A_17/54_Usine_de_Chorzow_Fond_Arret.pdf. Acesso em: 24 out. 2019. 
PERMANENT COURT OF INTERNATIONAL JUSTICE. Collection of judgments. Rights of minorities in Upper Silesia: (minority Schools). Leyden: A. W. Sijthoff's Publishing Company, 1928b. Disponível em: https:/www.icj-cij.org/public/files/permanent-court-of-internationaljustice/serie_A/A_15/46_Droits_de_minorites_en_Haute_Silesie_Ecoles_minoritaires_Arret.pdf. Acesso em: 11 nov. 2019.

PERMANENT COURT OF INTERNATIONAL JUSTICE. Judgments, orders and advisory opinion. Access to German minority Schools in Upper Silesia. Leyden: A. W. Sijthoff's Publishing Company, 1931. Disponível em: https://www.icj-cij.org/public/files/permanent-court-of-international-justice/ serie_AB/AB_40/01_Ecoles_minoritaires_Avis_consultatif.pdf. Acesso em: 14 nov. 2019.

PERMANENT COURT OF INTERNATIONAL JUSTICE. Judgments, orders and advisory opinion. Interpretation of the Statute the Memel Territory. Leyden: A. W. Sijthoff's Publishing Company, 1932. Disponível em: https://www.icj-cij.org/public/files/permanent-court-of-international-justice/ serie_AB/AB_49/01_Memel_Arret.pdf. Acesso em: 22 nov. 2019.

PERMANENT COURT OF INTERNATIONAL JUSTICE. Judgments, orders and advisory opinion. Case concerning the Polish Agrarian reform and the German minority: (interim measures of protection). Leyden: A. W. Sijthoff's Publishing Company, 1933. Disponível em: https://www. icj-cij.org/public/files/permanent-court-of-international-justice/serie_AB/AB_58/01_Reforme_ agraire_polonaise_Ordonnance_19330729.pdf. Acesso em: 18 nov. 2019.

PERMANENT COURT OF INTERNATIONAL JUSTICE. Judgments, orders and advisory opinion. Minority schools in Albania. Leyden: A. W. Sijthoff's Publishing Company, 1935. Disponível em: https://www.icj-cij.org/public/files/permanent-court-of-international-justice/serie_AB/AB_64/01_ Ecoles_minoritaires_Avis_consultatif.pdf. Acesso em: 20 nov. 2019.

SUBTELNY, Orest. Ukraine: a history. 4. ed. Toronto, Buffalo, London: University of Toronto Press, 2009.

THE TREATY of peace between the allied and associated powers and Turkey signed at Sèvres, 10 Aug. 1920. In: MARTIN, Lawrence. The treaties of peace: 1919-1923. New York: Carnegie Endowment for International Peace, 1924. Disponível em: https://wwi.lib.byu.edu/index.php/ Section_I,_Articles_1_-_260. Acesso em: 16 out. 2019. v. 2.

TREATY between the principal allied and associated Powers (the British Empire, France. Italy, Japan ans United States), and the Serb-Croat-Slovene State. Saint Germain-en-Laye, Sept. 1919a. Disponível em: http:/www.austlii.edu.au/au/other/dfat/treaties/1920/3.html. Acesso em 16 out. 2019.

TREATY between the principal allied and associated powers (the British Empire, France. Italy, Japan and the United States), and the Serb-Croat-Slovene State, signed at St. Germain-en-Laye (1919, 10 September). In: Parry, Clive (ed.). The consolidated treaty series, New York: Dobbs Ferry, 1919b. v. 226. p. 182-191. Disponível em: http://ungarisches-institut.de/dokumente/pdf/191909103.pdf. Acesso em: 16 out. 2019. 
TREATY between the principal allied and associated powers and Roumania, signed at Paris, December 9, 1919. In: LEAGUE OF NATIONS. Treaty Series, Geneva, v. 5, p. 336-347, 1921a. Disponível em: http://www.worldlii.org/int/other/LNTSer/1921/63.html. Acesso em: 16 out. 2019.

TREATY between the principal allied and associated powers, and Greece, concerning the protection of minorities in Greece, (Sèvres, 10 August 1920). In: AUSTRALIA. Department of Foreign Affairs and Trade. Australian Treaty Series, Canberra, n. 2, 1999. Disponível em: http://www.pollitecon. $\mathrm{com} / \mathrm{html} / \mathrm{treaties} /$ Treaty_Concerning_The_Protection_Of_Minorities_In_Greece.htm. Acesso em: 17 out. 2019.

TREATY of peace between the allied and associated Powers and Hungary and Protocol and Declaration. Trianon, June, 1920. Disponível em: http://hungarianhistory.com/lib/trianon/trianon. pdf. Acesso em: 16 out. 2019.

TREATY of peace between the principal allied and associated powers and Bulgaria and Protocol. Neuilly-sur-Seine, Nov. 1919. In: USA. Peace treaties: various treaties and agreements between the allied and associated powers and the Serb-Croat-Slovene State, Roumania, Bulgaria, Hungary, and Turkey: together with certain other agreements signed by the peace Conference at Paris and Saint Germain-en-Laye. Washington, DC: Government Printing Office, 1921b. Disponível em: https:// archive.org/stream/peacetreaties00alli\#page/46/mode/2up. Acesso em: 16 out. 2019.

TREATY of peace with Germany: (Treaty of Versailles). Versailles, June 1919c. Disponível em: https://www.loc.gov/law/help/us-treaties/bevans/m-ust000002-0043.pdf. Acesso em: 23 out. 2019.

TREATY of peace with Turkey. Lausanne, July 1923. Disponível em: http://sam.baskent.edu.tr/ belge/Lausanne_ENG.pdf. Acesso em: 16 out. 2019. 
